\title{
Calmodulin-Binding Transcription Activator 1
}

National Cancer Institute

\section{Source}

National Cancer Institute. Calmodulin-Binding Transcription Activator 1. NCI Thesaurus. Code C101442.

Calmodulin-binding transcription activator 1 (1673 aa, 184 kDa) is encoded by the human CAMTA1 gene. This protein is involved in the modulation of gene transcription. 